\title{
Ocular abnormalities associated with cerebral palsy after preterm birth
}

\begin{abstract}
Purpose To document the ocular abnormalities in children with cerebral palsy (CP) after premature birth.

Methods All the children born before 32 weeks gestation between 1 January 1990 and 31 December 1991 in a geographically defined population of approximately 3 million, were examined by an ophthalmologist and a paediatrician at 2 years old.

Results Five hundred and fifty-eight children (98.8\% of the study group) were examined, of whom 41 had disabling CP and 13 had nondisabling CP. Children with CP had a higher incidence of abnormalities compared with children without CP: cicatricial retinopathy of prematurity occurred in 8 children with $\mathrm{CP}$ (14.8\%) compared with 8 without CP $(1.6 \%$, $p<0.0001)$, cortical visual impairment occurred in 6 with CP (11.1\%) compared with 1 child without $C P(0.2 \%, p<0.0001)$ and concomitant strabismus in 28 with CP $(51.9 \%)$ compared with 42 without CP $(8.4 \%$, $p<0.0001$ ). The prevalence of refractive error without other ocular abnormalities was similar for children with CP $(4 / 54,7.4 \%)$ and those without CP (54/504, 10.7\%, $p=0.90)$. Significant ocular abnormalities had been previously unrecognised in 8 children with $\mathrm{CP}$ (14.8\%).
\end{abstract}

P.M. Pennefather

Department of

Ophthalmology

Royal Victoria Infirmary

Newcastle upon Tyne, UK

W. Tin

Regional Maternity

Survey Office

Newcastle upon Tyne, UK

Mrs P.M. Pennefather Department of

Ophthalmology

Royal Liverpool

University Hospital

Prescot Street

Liverpool L7 8XP, UK

Received: 15 April 1999 Accepted in revised form: 22 September 1999 Key words Cerebral palsy, Ocular abnormalities

Cerebral palsy (CP) is associated with an increased risk of ocular abnormalities, ${ }^{1,2}$ particularly strabismus ${ }^{3}$ and cortical visual impairment (CVI). ${ }^{4} \mathrm{CP}$ is the motor manifestation of non-progressive brain damage sustained during the period of brain growth. ${ }^{4}$ The timing, severity and aetiology of such brain damage is very varied. ${ }^{5}$ Therefore the incidence of associated ocular abnormalities is likely to vary according to the case selection of $\mathrm{CP}$ patients studied. Previous reports have studied only the severe end of the spectrum of $\mathrm{CP}^{3}$ or severe visual impairment. ${ }^{1,6}$ To avoid this selection bias, we have investigated the incidence of ocular abnormalities in children with CP associated with preterm birth in a geographically defined population.

\section{Methods}

The study group consisted of all children born before 32 weeks gestation between 1 January 1990 and 31 December 1991 to mothers resident in the Northern Region of the UK National Health Service who survived until 2 years old. This region has a population of approximately 3 million. Informed parental consent and ethics committee approval were obtained.

\section{Examination of children at 2 years}

All surviving neonates were reviewed by one paediatrician between the age of 2 years and 2 years 3 months. The history and examination included medical, neurological, developmental and hearing assessment. Children with $\mathrm{CP}$ were grouped according to the severity of $\mathrm{CP}$ into two categories: non-disabling $\mathrm{CP}$ or disabling CP. Disabling CP was defined as CP severe enough to hamper physical activity appropriate to the child's age whereas non-disabling $\mathrm{CP}$ was defined as CP with abnormalities of muscle tone and reflexes but insufficient to prevent the child performing normal activities for its age. Thus non-disabling CP usually consisted of a mild hemiplegia or monoplegia.

All 2-year-olds were also reviewed (on a separate occasion) by one ophthalmologist who was masked to gestational age at birth, neonatal events, the results of the paediatrician's assessment and retrospective review of the notes. Examination comprised visual acuity (usually by Kay pictures or grating acuity), cover tests for near and distant targets, extraocular movements and fields to confrontation. Topical cyclopentolate $1 \%$ was instilled $20 \mathrm{~min}$ prior to refraction and fundoscopy. 
Table 1. Ocular abnormalities in children with cerebral palsy $(C P)$ born before 32 weeks gestation, according to gestational age at birth

\begin{tabular}{|c|c|c|c|c|c|c|}
\hline $\begin{array}{l}\text { Gestational } \\
\text { age (weeks) }\end{array}$ & $\begin{array}{c}\text { No. with } \mathrm{CP} \\
\text { (\% total) }\end{array}$ & CVI & $\begin{array}{c}\text { Cicatricial } \\
\text { ROP }\end{array}$ & $\begin{array}{c}\text { Strabismus } \\
\text { (excluding CVI } \\
\text { and cicatricial ROP) }\end{array}$ & $\begin{array}{c}\text { Refractive error }^{\mathrm{a}} \\
\text { (excluding CVI, } \\
\text { cicatricial ROP, } \\
\text { and strabismus) }\end{array}$ & $\begin{array}{l}\text { Normal ocular } \\
\text { examination }\end{array}$ \\
\hline $23-23.9$ & $1(25.0)$ & & & & & 1 \\
\hline $24-24.9$ & $2(25.0)$ & & 2 & & & \\
\hline $25-25.9$ & $4(21.1)$ & 1 & 3 & & & \\
\hline $26-26.9$ & $3(11.5)$ & 1 & & 1 & 1 & \\
\hline $27-27.9$ & $11(21.2)$ & $1^{b}$ & 1 & 5 & 1 & 3 \\
\hline $28-28.9$ & $7(10.4)$ & & & 3 & & $4^{c}$ \\
\hline $29-29.9$ & $11(11.5)$ & 2 & & 3 & 1 & 5 \\
\hline $30-30.9$ & $10(7.1)$ & 1 & 1 & 4 & 1 & 3 \\
\hline $31-31.9$ & $5(3.4)$ & & & 3 & & 2 \\
\hline Total (\%) & $54(9.7)$ & $6(11.1)$ & 7 (13.0) & $19(35.2)$ & $4(7.4)$ & $18(33.3)$ \\
\hline
\end{tabular}

CVI, cortical visual impairment.

${ }^{a}$ Refractive error was defined as hypermetropia $>4$ dioptres, astigmatism of $>1.25$ dioptres, anisometropia of 1 dioptre or more or myopia of -0.25 dioptres or worse.

${ }^{\mathrm{b}}$ Also had cicatricial retinopathy of prematurity (ROP).

'One child had peripheral cryotherapy scars after treatment for threshold stage 3 acute ROP.

\section{Retrospective review of patient records}

Once the child had been examined, all available notes were scrutinised for information concerning screening for acute retinopathy of prematurity (ROP) and its treatment by cryotherapy. Any additional information such as the outcome of ocular examination under anaesthetic, electrodiagnostic studies or computed tomography of the head, was used to augment that obtained from clinical examination.

\section{Results}

Of the 565 eligible children, 558 2-year-olds (98.8\% of the study group) were examined by both the paediatrician and the ophthalmologist. Disabling CP was present in 41 $(7.3 \%)$ and non-disabling CP in 13 children $(2.3 \%)$. The distribution of ocular abnormalities according to gestational age at birth is shown in Table 1 for children with CP and in Table 2 for those without CP.

Comparison between children with $\mathrm{CP}$ and those without CP showed a higher prevalence of ocular abnormalities in children with CP: cicatricial ROP occurred in 8 of 54 compared with 8 of $504(p<0.0001)$, cortical visual impairment occurred in 6 of 54 compared with 1 of $504(p<0.0001)$ and strabismus occurred in 28 of 54 compared with 42 of $504(p<0.0001)$. Even excluding those children with strabismus associated with cicatricial ROP or CVI, the prevalence of strabismus was higher in children with CP $(19 / 54)$ compared with those without CP $(36 / 504, p<0.0001)$. The prevalence of refractive error without other ocular abnormalities was similar for children with CP $(4 / 54,7.4 \%)$ and those without CP $(54 / 504,10.7 \%, p=0.90)$.

\section{Ocular abnormalities in children with $\mathrm{CP}$}

Severe visual impairment (sufficient to cause nystagmus) occurred in $9(16.7 \%)$ children, namely all 6 children with CVI and 3 with bilateral cicatricial ROP. A further 4 children had cicatricial ROP but had vision in at least one

Table 2. Ocular abnormalities in children without cerebral palsy (CP) born before 32 weeks gestation, according to gestational age at birth

\begin{tabular}{|c|c|c|c|c|c|c|}
\hline $\begin{array}{l}\text { Gestational } \\
\text { age (weeks) }\end{array}$ & $\begin{array}{l}\text { No. without } C P \\
(\% \text { total })\end{array}$ & CVI & $\begin{array}{c}\text { Cicatricial } \\
\text { ROP }\end{array}$ & $\begin{array}{c}\text { Strabismus } \\
\text { (excluding CVI } \\
\text { and cicatricial ROP) }\end{array}$ & $\begin{array}{l}\text { Refractive error }{ }^{\mathrm{a}}{ }^{\text {(excluding CVI, }} \\
\text { cicatricial ROP, } \\
\text { and strabismus) }\end{array}$ & $\begin{array}{l}\text { Normal ocular } \\
\text { examination }^{\mathrm{b}}\end{array}$ \\
\hline $23-23.9$ & $3(75.0)$ & & 2 & & & 1 \\
\hline $24-24.9$ & $6(75.0)$ & & 1 & 1 & 2 & 2 \\
\hline $25-25.9$ & 15 (78.9) & & 1 & & 4 & 10 \\
\hline $26-26.9$ & $23(88.5)$ & & 1 & 4 & 2 & 16 \\
\hline $27-27.9$ & $41(78.8)$ & & 1 & 4 & 2 & 34 \\
\hline $28-28.9$ & 60 (89.6) & & 1 & 5 & 4 & 50 \\
\hline 29-29.9 & 85 (88.5) & & 1 & 3 & 7 & 74 \\
\hline 30-30.9 & $130(92.9)$ & & & 12 & 17 & 101 \\
\hline 31-31.9 & $141(96.6)$ & 1 & & 7 & 16 & 117 \\
\hline Total (\%) & $504(90.3)$ & $1(0.2)$ & $8(1.6)$ & $36(7.1)$ & 54 (10.7) & $405(80.4)$ \\
\hline
\end{tabular}

CVI, cortical visual impairment.

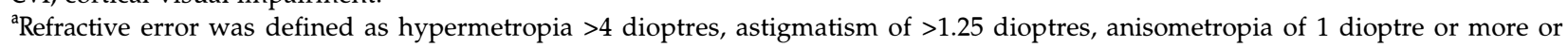
myopia of -0.25 dioptres or worse.

${ }^{b}$ These children include 4 with lid abnormalities, 2 with optic disc drusen, 1 with tilted discs, 1 with the left disc slightly smaller than the right and 1 with slight left disc pallor in association with ipsilateral ventricular dilatation (born at 28 weeks gestation). 
eye which was normal (2) or potentially normal when corrected for high myopia (2). The child with CVI and cicatricial ROP had received cryotherapy. Of the remaining 7 children with cicatricial ROP, 4 had received cryotherapy for threshold acute ROP, 2 had not been screened and 1 had been screened but did not reach threshold acute ROP and therefore had not received cryotherapy. A further 2 children who had received cryotherapy for threshold acute ROP had normal posterior poles when examined at 2 years old.

Optic disc pallor was present in both eyes of 2 children. The assessment of visual acuity was very limited. In addition to the children with severe visual impairment associated with nystagmus $(n=9)$, no measure of vision was achieved in 7, 13 demonstrated the ability to fix and follow a light and a face and 25 were able to perform vision assessment with Kay pictures ( 2 children achieved $6 / 18,3$ achieved $6 / 12,6$ achieved $6 / 9$ and 14 achieved $6 / 6$ or better). In comparison, only 3 children without $\mathrm{CP}$ had severe visual loss associated with nystagmus and 425 of $558(76 \%)$ achieved $6 / 9$ or better using Kay pictures.

Strabismus was present in 28 (51.9\%) of those with CP. Prior to any surgery, $24(44.4 \%)$ had an esotropia and $4(7.4 \%)$ had an exotropia. The ratio of esotropia to exotropia in those with CP (85.7\%:14.3\%) was almost the same as the ratio in the cohort of premature neonates as a whole $(84.3 \%: 15.7 \%)$.

Ocular examination was normal in 17 children $(31.5 \%)$. One other child had peripheral cryotherapy scars after treatment for threshold stage 3 acute ROP but the ocular examination was otherwise normal. A further 4 had a significant refractive error (anisometropia of 1.75-2.25 dioptres or astigmatism of 2.50-3.00 dioptres) requiring spectacles, but no other abnormality.

Screening revealed previously undetected ocular abnormalities in 5 children: 2 children had cicatricial ROP, 2 had strabismus and 1 was myopic with anisometropia. A further 3 children had not attended follow-up for strabismus and were identified by screening as requiring spectacles for hypermetropia (4-4.50 dioptres) or anisometropia (1 dioptre).

\section{Discussion}

$\mathrm{CP}$ is multifactorial with considerable diversity in the aetiology and timing of cerebral damage. ${ }^{5} \mathrm{CP}$ associated with prematurity is usually due to perinatal cerebral ischaemia or haemorrhage. ${ }^{5,8}$ Ultrasound evidence of severe ischaemic brain damage in premature neonates has been associated with an increased prevalence of severe acute ROP. ${ }^{8,9}$ Further, decreasing gestational age at birth is associated with an increased incidence of both $\mathrm{CP}^{7}$ and ROP. ${ }^{10}$ This is consistent with the high incidence of cicatricial ROP found in this study of CP after premature birth. Also 2 children with cicatricial ROP had not been adequately screened for acute ROP and therefore cicatricial changes may have been avoidable had they been screened and treated with cryotherapy if indicated. ${ }^{10}$
The prevalence of severe visual loss in this study group $(16.7 \%)$ was higher than previous reports of $5-7 \%$ of children with $\mathrm{CP} .{ }^{2,6}$ This may reflect the nature of cerebral damage in premature neonates with $\mathrm{CP}$ compared with children with CP of all aetiologies, ${ }^{5}$ as well as the contribution made by cicatricial ROP to severe visual loss. Strabismus is more common in CP than in the general population (approximately $3 \%$ at 2-3 years old). ${ }^{11}$ However, the reported prevalence of strabismus in CP varies from $19 \%$ to $50 \%$. ${ }^{3,6}$ Those studies with a relatively low prevalence ${ }^{6}$ may have underestimated the number of children with strabismus as children were not screened by an ophthalmologist or orthoptist and records were not available for many children. Black ${ }^{3}$ has previously reported a high (approximately 50\%) prevalence of strabismus in children with severe $\mathrm{CP}$ and mental retardation. The present study shows a similar prevalence even though a quarter of children had milder, non-disabling $\mathrm{CP}$. Interestingly, Black showed $15 \%$ of strabismus to be incomitant, whereas in the present study all strabismus was concomitant. This probably reflects the more diverse aetiology of $\mathrm{CP}$ in his cases, with a childhood onset in some patients.

Refractive errors are not usually documented in studies of $\mathrm{CP} .{ }^{2,6}$ However, Black ${ }^{12}$ noted $49.6 \%$ of 6 to 16-year-olds with severe $\mathrm{CP}$ and mental retardation had a refractive error of more than 2 dioptres of hypermetropia or 1 dioptre of myopia. Some of these refractive errors were not sufficient to benefit from spectacle correction. In this study, spectacles contributed to the management of some of the children with cicatricial ROP and strabismus but it is also important to identify those children with an isolated refractive error if this is sufficient to cause amblyopia. ${ }^{13}$

Children with CP after premature birth form an increasingly important sub-group of CP patients. 2,14,15 Although the incidence of CP has declined in those born at between 28 and 32 weeks gestation due to improved neonatal care, the overall proportion of premature neonates with CP has remained almost unchanged due to an increase in survival of those born before 28 weeks gestation. ${ }^{14}$ Further, this increased survival of premature neonates, together with an increase in the number of children born prematurely, ${ }^{14}$ has resulted in an increase in the total number of children with CP after premature birth. ${ }^{2,14,15}$

The high frequency of abnormalities with therapeutic and educational significance highlights the importance of ocular assessment of these children. The number of children whose ocular abnormality had not been suspected prior to screening emphasises how easy it is to miss visual abnormalities in children whose poor performance can be attributed to other problems.

We are grateful to Mr Michael P. Clarke, Mr David G. Cottrell and Dr Edmund Hey for advice. 


\section{References}

1. Murphy CC, Yeargin-Allsopp M, Decoufle P, Drews CD. Prevalence of cerebral palsy among ten-year-old children in metropolitan Atlanta, 1985 through 1987. J Pediatr 1993;123:S13-20.

2. Robertson CMT, Hrynchyshyn GJ, Etches PC, Pain KS. Population-based study of the incidence, complexity and severity of neurologic disability among survivors weighing 500 through 1250 grams at birth: a comparison of two birth cohorts. Pediatrics 1992;90:750-5.

3. Black P. Visual disorders associated with cerebral palsy. Br J Ophthalmol 1982;66:46-52.

4. Brown JK. Disorders of the central nervous system. In: Textbook of paediatrics. London: Churchill Livingstone, 1992:802-33.

5. Stanley FJ. The aetiology of cerebral palsy. Early Hum Dev 1994;36:81-8.

6. Evans P, Elliott M, Alberman E, Evans S. Prevalence and disabilities in 4 to 8 year olds with cerebral palsy. Arch Dis Child 1985;6:940-5.

7. Fernell E, Hagberg G, Hagberg B. Infantile hydrocephalus epidemiology: an indicator of enhanced survival. Arch Dis Child 1994;70:FD123-8.
8. Ng YK, Fielder AR, Levene MI, Trounce JQ, McLellan N. Are severe acute retinopathy of prematurity and severe periventricular leucomalacia both ischaemic insults? Br J Ophthalmol 1989;73:111-4.

9. Hungerford J, Stewart A, Hope P. Ocular sequelae of preterm birth and their relation to ultrasound evidence of cerebral damage. Br J Ophthalmol 1986;70:463-8.

10. Cryotherapy for Retinopathy of Prematurity Cooperative Group. Multicenter trial of cryotherapy for retinopathy of prematurity: three months outcome. Arch Ophthalmol 1990;108:195-203.

11. Graham PA. Epidemiology of strabismus. Br J Ophthalmol 1974;58:224-31.

12. Black PD. Ocular defects in children with cerebral palsy. BMJ 1980;II:487-8.

13. Freedman HL, Preston KL. Polaroid photoscreening for amblyogenic factors: an improved methodology. Ophthalmology 1992;99:1785-95.

14. Tin W. Changing prognosis of babies born more than eight weeks early over the decades [abstract]. British Paediatric Association 66th annual meeting, University of Warwick, 12-15 April 1994.

15. Bhushan V, Paneth N, Kiely JL. Impact of improved survival of very low birth weight infants on recent secular trends in the prevalence of cerebral palsy. Pediatrics 1993;91:1094-110. 